\title{
GABRIC Diabetes School: an innovative education centre for people with diabetes
}

Alireza Esteghamati ${ }^{1}$, Farhad Hosseinpanah ${ }^{2}$, Seyed Adel Jahed ${ }^{3}$, Hadi Harati ${ }^{3}$, Mohammad Taghi Cheraghchi Bashi Astaneh ${ }^{3}$, Hormoz Kaykhanzadeh ${ }^{3}$ and Sara Sedaghat ${ }^{3}$

${ }^{1}$ Endocrinology and Meatbolism Research Center, Vali-Asr Hospital School of Medicine, Tehran University of Medical Sciences, Tehran, Islamic Republic of Iran ${ }^{2}$ Obesity research center, Research institute for Endocrine Sciences, Shahid Beheshti University of Medical Sciences, Tehran, Islamic Republic of Iran ${ }^{3}$ Gabric Diabetes Education Association, Tehran, Islamic Republic of Iran (Correspondence to: Sara Sedaghat: s.sedaghat@gabric.ir).

\begin{abstract}
Diabetes prevalence and deaths attributable to diabetes continue to rise across globally. Diabetes Self-Management Education and Support (DSME/S) is a critical resource designed to help people with diabetes (PWD) successfully selfmanage their disease; however, its utilization is too low. In the Islamic Republic of Iran, there are currently limited structured educational programmes and no national standards for DSME/S protocol. In response to this, the GABRIC Diabetes Education Association (GDEA) has been developed as a school for diabetics, which has a comprehensive DSME/S programme for PWD with 18 distinct courses on 5 levels for 8 target groups. In addition, GABRIC has developed a database registry with more than 100000 members throughout the country, of whom $95 \%$ are diabetic with a proportion of $82 \%$ Type 2 diabetes and 13\% Type 1 diabetes. The success of the GABRIC school model results is yet to be investigated through study trials, and offers a fruitful line of research.
\end{abstract}

Keywords: Diabetes, diabetic, education, self-management, noncommunicable diseases

Citation: Esteghamati A, Hosseinpanah F, Adel Jahed S, Harati H, Astaneh MTCB, Kaykhanzadeh H, et al. GABRIC diabetes school: an innovative education centre for diabetics. East Mediterr Health J. 2018;24(1):99-103. https://doi.org/10.26719/2018.24.1.99

Received: 06/01/18; accepted: 17/01/18

Copyright (C) World Health Organization (WHO) 2018. Some rights reserved. This work is available under the CC BY-NC-SA 3.0 IGO license (https:// creativecommons.org/licenses/by-nc-sa/3.o/igo)

\section{Introduction}

Diabetes is one of the largest global health emergencies of the 21st century and the epidemic is expected to continue (1). Diabetes prevalence, deaths attributable to diabetes, and health expenditure due to diabetes continue to rise across the globe with important social, financial and health system implications (2). Despite the fact that Diabetes Self-Management Education and Support (DSME/S) is such a critical resource to help people with diabetes successfully self-manage their disease, its utilization is too low $(3,4)$. DSME/S are essential elements of diabetes care that have been shown to improve the haemoglobin Aic (HbAic) level by as much as $1 \%$ in people with Type 2 diabetes (T2DM), aside the positive effects on other clinical, psychosocial, and behavioural aspects of diabetes $(5,6)$.

Qualitative studies have shown that educational barriers are among the main perceived barriers for patients with diabetes (7). Despite this fact, there are limited educational programmes in the Islamic Republic of Iran for people with diabetes and no national standard DSME/S protocol has been implicated in the country (8). Shakibzadeh et al. developed a Persian DSME and evaluated its efficacy (8). Thus, the GABRIC Diabetes Education Association (GDEA) was developed with a comprehensive DSME/S programme to provided education and support for all people with diabetes (PWD). Founded in 2006 in Tehran, GDEA is a nongovernmental organization and an official member of the International Diabetes Federation (IDF). It was developed by a group of endocrinologists and young "well controlled" patients with Type 1 diabetes (T1DM). GDEA has subsequently flourished and seeks to improve the lives of PWD and to promote primary, secondary and tertiary diabetes prevention via education, raising awareness, and building motivation. Having T1DM has always been an important recruitment criteria; a notion that has proved necessary for delivering an empathetic education and support.

\section{GABRIC's mission and vision}

GABRIC's mission and vision can be summarized by the following: "In GABRIC we strive to proscribe diabetes complications by prescribing awareness and motivation", and "We Gabricians will create a future in which diabetes will no longer be a serious public concern and all persons with diabetes can live a productive and fulfilling life."

\section{Building motivation: a psychological recruitment strategy}

The American Diabetes Association (ADA) recommends that all PWD should receive DSME (9), but evidence shows that the utilization of DSME is still too low. Therefore, programmes need to become more innovative regarding ways to attract PWD $(3,4,10)$, who often strongly believe that they get the DSME they need from their physicians (10), making it a difficult task to convince them to participate in DMSE/S programmes.

Although engaging PWD in DSME/S is not an easy task in the Iranian/Middle Eastern culture, GABRIC has utilized "empathy" by peers as a motivating factor for PWD to become active members of their treatment 
team; i.e., the contact point of every PWD would be a well-controlled peer, who has been trained to provide empathy and lead peer support through an interactive motivational interview, and convince the PWD to get involved in the DSME/S programme.

\section{Collective education: learning with a diabetes educator and building skills with peers}

GABRIC DSME has been delivered via a "diabetes school" model, categorized into 18 distinct courses at 5 levels including elementary, intermediate, advanced and complementary. Thus, covering the educational needs for 8 target groups including PWD, the population at risk of diabetes, as well as care givers and healthcare professionals (HCP) (Table 1).

There is growing evidence for the role of peers and lay leaders in providing ongoing support (11). The World Health Organization (WHO) Consultation on Peer Support Programmes in Diabetes documents the promise of peer support as an effective approach to chronic disease management and health promotion (12). Peer support could allow patients to share experiences and receive the reinforcement that is not attainable from time-pressed clinicians, and it may especially benefit patients who are tackling challenging medical tasks, such as insulin management (13).

The majority of the staff at GDEA have TiDM, some of whom are trained in the role of peer support. They will provide motivation, facilitate skill trainings (e.g., insulin injection and self-monitoring of blood glucose), and provide ongoing support through follow-up contact. The implementation of active peer support to facilitate behaviour change through motivational interviewing is the cornerstone of GABRIC DSME/S. Moreover, GABRIC's diabetes education advisory committee - involving endocrinologists, nutritionists and PWD in defining educational policies - provides the opportunity for a multi-aspect approach to the standard DSME instructed by diabetes educators.

\section{Experiential learning model}

In the four-stage experiential learning model, personal experience is the key to behaviour change and selfefficacy. Therefore, people need to actively be involved in the situation and it is up to the educator to facilitate the learning process (14). Diabetes educators in GABRIC's group education classes use the "Experiential Learning Model" along with homework, logbooks, reviews, case studies and role modeling to involve people in the problem-solving process and use real situations to help learners gain insight (15).

\section{Patient specific education path: education is individualized}

GABRIC Diabetes School has 18 distinct courses in elementary, intermediate, advanced and complementary levels. Every person with diabetes might be included in a specific education path based on their needs. For example, an adult with T2DM will have a specific education path including weight management, ABC's of diabetes and stress management, while a child with T1DM will have their own specific education path including the "Keepo Adventure" course.

A distinct special level is also defined that includes national programmes as well as HCP training courses including "Basics of Diabetes Education" (a 15-hour long course for diabetes educators), and a "Diabetes Ambassadors Workshop" that is specifically designed to train nurses regarding communication skills and strategies to prevent diabetes emergencies. Insulin My Friend (IMF) is a national campaign specifically designed for deprived areas across the Islamic Republic of Iran. It started as a 2-day educational campaign targeting persons with T1DM and HCPs in 2011. Recently, this course has been expanded to a 3-day education programme to cover people with T2DM and primary health care providers; up until now 16 cities have been covered across country, totaling 2800 PWD and $2000 \mathrm{HCP}$ involved in this educational campaign, using 23000 man hours.

\section{"Keepo Adventures": empowering children and families}

Schoolchildren depend on peer decision-making in their daily lives. They need age-adapted information on the disease, its treatment, and the appropriate conduct in difficult situations such as hypoglycaemia. Although the main responsibility for the therapy lies with the parents, every child in this age group is offered a structured education that promotes a secure childhood with as few restrictions as possible $(16,17)$. The "Keepo Adventures" course, a 6-hour training course conducted through two sessions one week apart, has been designed to fulfill the educational needs of children aged 7 to 12 years. It comes with counseling sessions for parents in order to learn how to deal with their new family life and acquire ageadapted information on diabetes management.

The Keepo cartoon character, developed in 2011 with an Iranian name meaning "butterfly" has T1DM and has arrived from an imaginary planet named Sugarland. The antennas on Keepo's head indirectly represent the body organs and highlight inappropriate glucose management through their disappearance. The presence of an imaginary character in Keepo Adventures courses develops the empathy of children, welcoming it as an intimate friend and will help them follow Keepo's rules.

\section{Organized data registry}

During its years of activity, GABRIC has developed a database registry with more than 104000 members throughout the Islamic Republic of Iran, 95\% of whom have diabetes based on self-discretion with a female/male ratio of $1 / 1.70 \%$ of members reside in Tehran. Our data registration reports the $\mathrm{T} 2 \mathrm{DM}$ and $\mathrm{T} 1 \mathrm{DM}$ population to be around $82 \%$ and $13 \%$ respectively. Around $5 \%$ have other 
Table 1 GABRIC diabetes school model

\begin{tabular}{|c|c|c|c|}
\hline Course title & $\begin{array}{l}\text { Target } \\
\text { group }\end{array}$ & $\begin{array}{l}\text { Number of } \\
\text { sessions }\end{array}$ & Comments \\
\hline \multicolumn{4}{|l|}{ Elementary } \\
\hline Elementary (E) & * & 1 & $\begin{array}{l}\text { Motivating diabetic patients in order to control diabetes, improving/ } \\
\text { modifying misconceptions, familiarization with factors affecting blood } \\
\text { glucose, emphasizing continuous visits to the doctor. }\end{array}$ \\
\hline Keepo Adventures (E-KA) & $\mathrm{D}$ & 2 & $\begin{array}{l}\text { Motivating and educating diabetes self- management skills for } \\
\text { children. }\end{array}$ \\
\hline Gestational diabetes (E-GDM) & $\mathrm{H}$ & 1 & $\begin{array}{l}\text { Healthy nutrition and physical activity recommendations, } \\
\text { familiarization with misconceptions, promoting mother and baby } \\
\text { health. }\end{array}$ \\
\hline \multicolumn{4}{|l|}{ Intermediate } \\
\hline Type 1 (I-T1) & $A, E$ & 3 & \multirow{2}{*}{$\begin{array}{l}\text { Knowing diabetes, the importance of self - glucose monitoring, } \\
\text { hypoglycaemia, principles of nutrition therapy, carbohydrates, } \\
\text { the importance of weight loss, the } A B C \text { of diabetes management, } \\
\text { prevention of complications and self - care, physical activity, insulin } \\
\text { injection techniques and different types of insulin. }\end{array}$} \\
\hline Type 2- Oral Agents (I- T20) & C & 2 & \\
\hline \multicolumn{4}{|l|}{ Advanced } \\
\hline Type 1 (I-T1) & $A, E$ & 2 & \multirow{3}{*}{$\begin{array}{l}\text { Meal planning in practice, practical carbohydrate counting, exercise } \\
\text { programme, pattern management of SMBG results and insulin } \\
\text { adjustment, questions and answers, travelling tips, hypoglycaemia } \\
\text { prevention in exercise and sick day care. }\end{array}$} \\
\hline Type 2-Insulin (I- T21) & B & 2 & \\
\hline Type 2 - Oral Agents (I - T20) & C & 2 & \\
\hline \multicolumn{4}{|l|}{ Complementary } \\
\hline Stress management (C-SM) & * & 1 & $\begin{array}{l}\text { Familiarization with stress and its symptoms, methods of stress } \\
\text { management, practical techniques of relaxation, practical techniques } \\
\text { of relaxation. }\end{array}$ \\
\hline Weight management (C-WM) & * & 1 & $\begin{array}{l}\text { Motivating in order to achieve the desired weight, how to reduce the } \\
\text { energy intake, physical activity principles. }\end{array}$ \\
\hline $\begin{array}{l}A B C(A 1 C \text {, blood pressure, cholesterol control } \\
\text { in diabetes }(C-A B C)\end{array}$ & * & 1 & $\begin{array}{l}\text { Modifying life style and nutrition in order to control blood pressure, } \\
\text { lipids and glucose. }\end{array}$ \\
\hline Parent discussion club & E & 2 & $\begin{array}{l}\text { Familiarization with each other and sharing their experiences, } \\
\text { presenting practical and psychological methods for effective } \\
\text { management of children's diabetes. }\end{array}$ \\
\hline GABRIC support session & A & 2 & $\begin{array}{l}\text { Utilizing advanced carbohydrate counting skills, problem solving, } \\
\text { individualized SMART goal setting, promoting self-assessment and } \\
\text { informed decision-making. }\end{array}$ \\
\hline
\end{tabular}

\begin{tabular}{|c|c|c|c|}
\hline $\begin{array}{l}\text { Health nutrition and diabetes prevention } \\
\text { (S-HNDP) }\end{array}$ & G & 1 & $\begin{array}{l}\text { Introducing practical ways for health nutrition and increasing physical } \\
\text { activity to prevent diabetes and promote healthy lifestyle. }\end{array}$ \\
\hline Insulin my friend (S - IMF) & $\mathrm{A}, \mathrm{F}$ & 4 & $\begin{array}{l}\text { A creative educational campaign targeting } \mathrm{T} 1 \text { diabetics and diabetes } \\
\text { educators. }\end{array}$ \\
\hline Basics of diabetes education (S-BDE) & $\mathrm{F}$ & 4 & $\begin{array}{l}\text { Training diabetes educators to get familiar with the educational } \\
\text { challenges of diabetics, how to teach scientific concepts in plain } \\
\text { language, how to teach necessary skills to patients. }\end{array}$ \\
\hline Diabetes ambassadors workshop (S - DAW) & $\mathrm{F}$ & 1 & $\begin{array}{l}\text { An educational course for nurses focused on diabetes emergencies } \\
\text { (hypo- and hyperglycaemic), sick day management and } \\
\text { communication skills. }\end{array}$ \\
\hline \multicolumn{4}{|l|}{ Courses are free of charge due to support from donors an } \\
\hline $\mathrm{A}=$ People with Type 1 diabetes & & \multicolumn{2}{|c|}{$E=$ Parents of children with Type 1 diabetes } \\
\hline B = People with Type 2 diabetes on insulin & & \multicolumn{2}{|c|}{$F=$ Health care professionals } \\
\hline$C=$ People with Type 2 diabetes on oral therapy & & \multicolumn{2}{|c|}{$G=$ General and risk population } \\
\hline$D=$ Children with Type 1 diabetes & & \multicolumn{2}{|c|}{$H=$ Mothers diagnosed with GDM } \\
\hline
\end{tabular}

specific types of diabetes. Up until January 2017, our total man-hours of education was 338268.

GABRIC's educational model was selected as the best practice of diabetes education in the Middle East and North Africa (MENA) region in 2010 by the MENA Diabetes Leadership Forum (18). In 2016, GDEA was invited to attend WHO's World Health Day event in Geneva, Switzerland, to present its diabetes school model.

\section{Limitations}

It is expected that DSME/S programmes result in behaviour change; whether the GABRIC Diabetes School 
model as a structured DSME/S facilitates behaviour change is yet to be investigated through research protocols. Although evidence shows that engaging DSME programmes results in a reduction in HbAlc levels in people with T2DM (19), whether our designed
DSME/S programme results in HbA1c reduction, lifestyle and psychological outcomes need to be determined by research. The same concept also applies to the role of empathy and peer support in motivating and engaging PWD in our DSME/S.

\section{Funding: None.}

Competing interests: None declared

\section{GABRIC, l'école du diabète : un centre d'éducation pour diabétiques innovant}

\section{Résumé}

La prévalence du diabète et les décès attribuables à cette maladie continuent d'augmenter dans le monde. L'éducation et l'appui à l'auto-prise en charge du diabète constituent une ressource essentielle mise au point pour aider les diabétiques à prendre en charge eux-mêmes leur maladie. Cependant, le recours à cette méthode reste trop faible. En République islamique d'Iran, les programmes d'éducation structurés sont actuellement en nombre limité, et il n'existe pas de normes nationales pour les protocoles d'éducation et d'appui à l'auto-prise en charge du diabète. Pour combler cette lacune, l'Association GABRIC d'éducation au diabète a été créée afin de jouer un rôle d'école pour diabétiques. Elle propose un programme complet d'éducation et d'appui à l'auto-prise en charge du diabète, composé de 18 cours distincts répartis en cinq niveaux destinés à huit groupes cibles. En outre, GABRIC a établi un registre de bases de données comprenant plus de 100000 membres à travers le pays, dont $95 \%$ de diabétiques, avec une proportion de $82 \%$ de diabète de type 2 , et $13 \%$ de diabète de type 1 . Le succès des résultats du modèle de l'école GABRIC reste à être examiné au moyen d'essais, et offre un axe de recherche constructif.

$$
\text { ملدرسة كابريكى لمرضى السكري: مر كز ابتكاري لتثقيف مرضى استقامتي، فرهاد حسين پيناه، سيد عادل جاهد، هادي هراتي، محمد تقي خر اغريى استانه، هرمز كيخان زاده، سارا صداقت }
$$

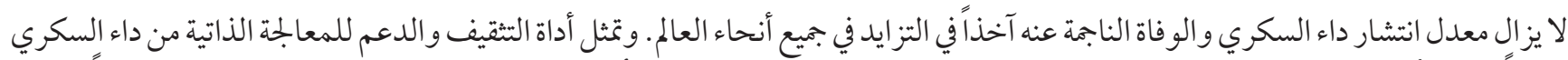

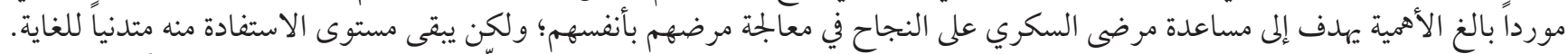

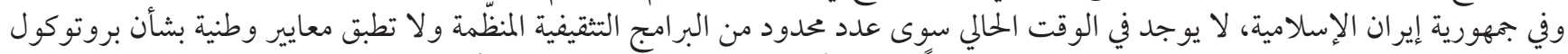

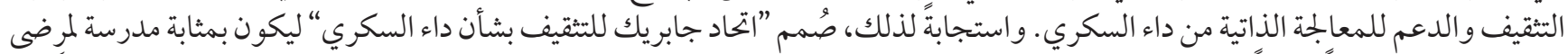

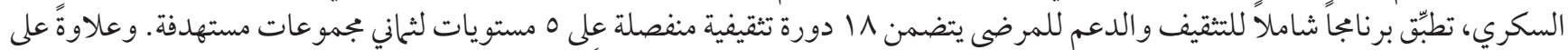

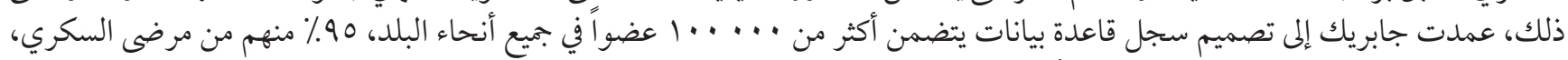

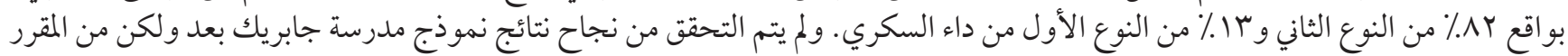

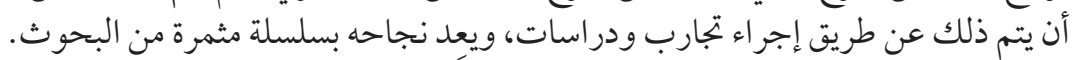

\section{References}

1. International Diabetes Federation. IDF Diabetes Atlas $8^{\text {th }}$ Ed. Brussels: IDF; 2017.

2. Ogurtsova K, da Rocha Fernandes JD, Huang Y, Linnenkamp U, Guariguata L, Cho NH, et al. IDF Diabetes Atlas: Global estimates for the prevalence of diabetes for 2015 and 2040. Diabetes Res Clin Pract. 2017 Jun;128:40-50. https://doi.org/10.1016/j. diabres.2017.03.024 PMID:28437734

3. Strawbridge LM, Lloyd JT, Meadow A, Riley GF, Howell BL. Use of Medicare's Diabetes Self-Management Training Benefit. Health Educ Behav. 2015 Aug;42(4):530-8. https://doi.org/10.1177/1090198114566271 PMID:25616412

4. Li R, Shrestha SS, Lipman R, Burrows NR, Kolb LE, Rutledge S; Centers for Disease Control and Prevention (CDC). Diabetes self-management education and training among privately insured persons with newly diagnosed diabetes-United States, 20112012. MMWR Morb Mortal Wkly Rep. 2014 Nov 21;63(46):1045-9. PMID:25412060

5. $\quad$ Norris SL, Lau J, Smith SJ, Schmid CH, Engelgau MM. Self-management education for adults with type 2 diabetes: a meta-analysis of the effect on glycemic control. Diabetes Care. 2002 Jul;25(7):1159-71. https://doi.org/10.2337/diacare.25.7.1159 PMID:12087014

6. Powers MA, Bardsley J, Cypress M, Duker P, Funnell MM, Fischl AH, et al. Diabetes self-management education and support in type 2 diabetes: a joint position statement of the American Diabetes Association, the American Association of Diabetes Educators, and the Academy of Nutrition and Dietetics. Diabetes Educ. 2017 Feb;43(1):40-53. https://doi.org/10.1177/0145721716689694 PMID:28118121 
7. Shakibazadeh E, Larijani B, Shojaeezadeh D, Rashidian A, Forouzanfar M, Bartholomew L. Patients' Perspectives on Factors that Influence Diabetes Self-Care. Iran J Public Health. 2011 Dec;40(4):146-58. PMID:23113114

8. Shakibazadeh E, Bartholomew LK, Rashidian A, Larijani B. Persian Diabetes Self-Management Education (PDSME) program: evaluation of effectiveness in Iran. Health Promot Int. 2016 Sep;31(3):623-34. https://doi.org/10.1093/heapro/davoo6 PMID:25761821

9. American Diabetes Association. Standards of medical care in diabetes 2017.

10. Peyrot M, Rubin RR, Funnell MM, Siminerio LM. Access to diabetes self-management education: results of national surveys of patients, educators, and physicians. Diabetes Educ. 2009;35(2):246-8, 52-6, 58-63.

11. Siminerio L, Ruppert KM, Gabbay RA. Who can provide diabetes self-management support in primary care? Findings from a randomized controlled trial. Diabetes Educ. 2013 Sep-Oct;39(5):705-13. https://doi.org/10.1177/0145721713492570 PMID:23782622

12. World Health Organization. Peer Support Programmes in Diabetes: Report of a WHO Consultation. Geneva: World Health Organization; 2008.

13. Heisler M, Vijan S, Makki F, Piette JD. Diabetes control with reciprocal peer support versus nurse care management: a randomized trial. Ann Intern Med. 2010 Oct 19;153(8):507-15. https://doi.org/10.7326/0003-4819-153-8-201010190-00007 PMID:20956707

14. Bergsteiner H, Avery GC, Neumann R. Kolb's experiential learning model: critique from a modelling perspective. Studies in Continuing Education. 2010;32(1):29-46. https://doi.org/10.1080/01580370903534355

15. Murrell PH, Claxton CS. Experiential learning theory as a guide for effective teaching. Counselor Education Supervision. 1987;27(1):4-14. https://doi.org/10.1002/j.1556-6978.1987.tboo735.x

16. Lange K, Sassmann H, von Schütz W, Kordonouri O, Danne T. Prerequisites for age-appropriate education in type 1 diabetes: a model programme for paediatric diabetes education in Germany. Pediatr Diabetes. 2007 Oct;8(s6) Suppl 6:63-71. https://doi. org/10.1111/j.1399-5448.2007.00277.x PMID:17727387

17. Chiang JL, Kirkman MS, Laffel LM, Peters AL; Type 1 Diabetes Sourcebook Authors. Type 1 diabetes through the life span: a position statement of the American Diabetes Association. Diabetes Care. 2014 Jul;37(7):2034-54. https://doi.org/10.2337/dc14-1140 PMID:24935775

18. Forum MDL. Diabetes: the hidden pandemic and its impact on Middle East \& North Africazo10.

19. Chrvala CA, Sherr D, Lipman RD. Diabetes self-management education for adults with type 2 diabetes mellitus: A systematic review of the effect on glycemic control. Patient Educ Couns. 2016 06;99(6):926-43. https://doi.org/10.1016/j.pec.2015.11.003 PMID:26658704 